\title{
New Approaches to Control Infections: Anti-biofilm Strategies against Gram- negative Bacteria
}

\author{
Roman Sommer ${ }^{\dagger}$, Ines Joachim ${ }^{\dagger}$, Stefanie Wagner, and Alexander Titz $\S^{\star *}$
}

§SCS-DSM Award for best poster presentation

\begin{abstract}
Hospital-acquired bacterial infections, especially with Gram-negative pathogens, present a major threat due to the rapid spread of antibiotic-resistant strains. Targeting mechanisms of bacterial virulence has recently appeared as a promising new therapeutic paradigm. Biofilm formation is a bacterial lifestyle, which offers a survival advantage through its protective matrix against host immune defense and antibiotic treatment. Interfering with biogenesis of adhesive organelles, bacterial communication or carbohydrate-mediated adhesion as anti-biofilm strategies are reviewed.
\end{abstract}

Keywords: Adhesion · Biofilm · Infection · Quorum sensing · Lectins

\section{Introduction}

Until Fleming's discovery of penicillin in the early $20^{\text {th }}$ century, bacterial infections had been a severe burden for humankind. The serendipitous identification of bactericidal activity originating from a fungus sparked the discovery of various antibiotics, which were soon used clinically as therapeutics against infections of bacterial origin. Several new classes of compounds with different mechanism of action were developed, targeting a diversity of essential processes in the bacterium. Inappropriate and excessive use, both as therapeutic for humans and as preventive food additive in meat production, has imposed a high selection pressure on bacteria and resistant mutants appeared. Antibiotic-resistant strains now pose a major problem in health care units and nosocomial infections by resistant strains led to $25^{\prime} 000$ deaths and extra costs of $€ 900$ million in the European Union in 2007.[1] Methicillin-resistant Staphylococcus aureus (MRSA) is a prominent Gram-positive bacterium and in recent years, resistant strains of Gram-negative Escherichia coli,

\footnotetext{
${ }^{\star}$ Correspondence: Dr. A. Titz

University of Konstanz

Department of Chemistry and Zukunftskolleg

Universitätsstrasse 10

D-78457 Konstanz

Tel.: +497531885628

E-mail: alexander.titz@uni-konstanz.de

${ }^{\dagger}$ Both authors contributed equally
}

Klebsiella pneumoniae and Pseudomonas aeruginosa appeared in hospital-acquired infections. In contrast to the single cellular membrane of Gram-positive bacteria, Gram-negative species possess an outer and an inner membrane reinforcing the physical barriers against drug treatment. In addition, a variety of bacterial efflux pumps remove exogenous compounds from the bacterial cell and render drugs ineffective. ${ }^{[2]}$ The development and approval of new antibiotics has severely slowed in the last decades, resulting in a relatively small arsenal against increasingly resistant bacteria towards existing antibiotics. One reason is the threat of a rapid development of resistant strains rendering new drugs inefficacious, implying a big financial burden for drug manufacturers. Margaret Chan, Director General of the WHO recently stated the current threat: "In terms of new replacement antibiotics, the pipeline is virtually dry, especially for Gramnegative bacteria."'[3]

In recent years, new strategies have emerged to control infections by targeting non-essential processes of the pathogen, which are needed for infection, rather than targeting its viability by traditional antibiotics, called anti-virulence therapy.[4] Potential drugs with mechanisms of action that do not interfere with the growth of the organism are expected to have a significantly lowered selection pressure and therefore a reduced occurrence of resistant mutants. The formation of biofilms is often observed in chronic infections. Biofilms are multicellular assemblies of bacteria embedded in a complex matrix and localized on implant or host tissue surfaces. In addition to the intrinsic and acquired resistances of pathogens which are based, e.g. on the use of efflux pumps, antibiotic-converting enzymes, or mutations in target proteins of the employed antibiotic, bacteria are further protected in the biofilm against antibiotic treatment and host cell defense and can thereby maintain chronic infections. ${ }^{5,6]}$ The synergistic action of these mechanisms of resistance often render infections untreatable. Therefore, the inhibition of biofilm formation, e.g. by interfering with bacterial communication systems $(\rightarrow$ targeting quorum sensing) required for its assembly, by blocking the biogenesis of adhesive organelles ( $\rightarrow$ targeting adhesive organelles: pilicides) or by dissolution of the biofilm by interference with the biofilm architecture $(\rightarrow$ targeting carbohydrate binding adhesins) are discussed (Fig. 1).

\section{Targeting Quorum Sensing}

Many Gram-negative bacteria use quorum sensing to stimulate expression of certain genes. The system was first discovered in Vibrio fischeri, and found responsible for bioluminescence through activation of the lux gene cluster. Small molecules (autoinducer) are constitutively produced by the bacterium and used as stimulus and response signals. Once a given concentration threshold is reached due to a high bacterial density, the autoinducer binds to its cytoplasmic receptor and subsequently transcription of genes, including the ones responsible for synthesis of the autoinducer, is activated and thereby amplified.[7] Often, quorum sensing results in a switch 


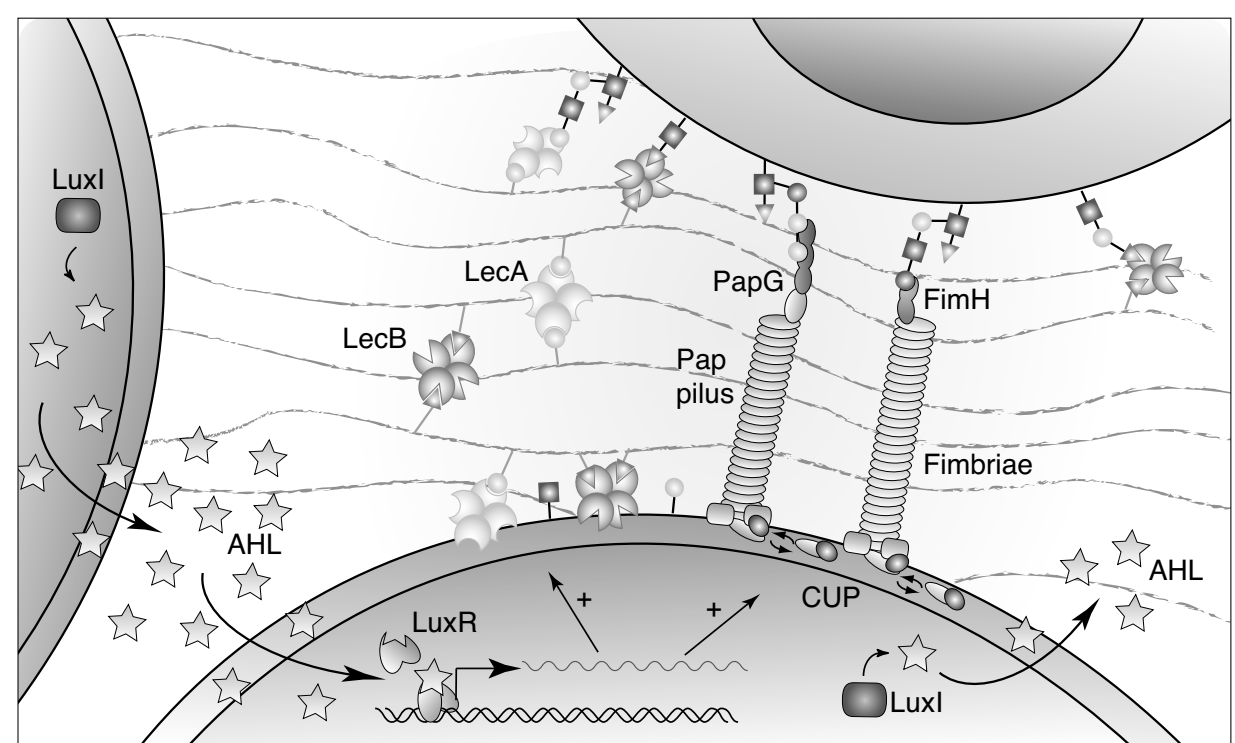

Fig. 1. Schematic representation of anti-biofilm targets in Gram-negative bacteria (see body text for details). in bacterial lifestyle from single cells to multicellular assemblies, i.e. biofilms. In Gram-negative bacteria, the autoinducer molecules $N$-acylated L-homoserine lactones (AHL) are synthesized by the inducer synthase (LuxI) and recognized by their cognate receptors (LuxR), and the complex then binds to DNA and induces expression of various genes. In $P$. aerugi$n o s a$, genes under quorum sensing control are responsible for the production of virulence factors like exotoxin A, pyocyanin, pyoverdine, cyanides and lectins (LecA, LecB), antibiotic resistance and biofilm formation. Interference with the quorum sensing cascade can reduce the expression of virulence factors as well as biofilm formation and is therefore a promising antivirulence strategy. ${ }^{[8,9]}$ sensing systems: las, rhl and pqs. The elastase genes (lasA, lasB) form the las system with the autoinducer synthase (LuxI homolog LasI) and the autoinducer $\mathrm{N}$-(3-oxododecanoyl)-L-homoserine lactone (1, OdDHL, Fig. 2). In the $r h l$ system $(r h l R / r h l l)$, the autoinducer $N$-butyroyl-Lhomoserine lactone $(2, \mathrm{BHL})$ is responsible for the biosynthesis of the biosurfactant rhamnolipids. Infection with $P$. aeruginosa impaired in lasI and rhlI gene expression resulted in a reduction of the mortality rate of thermally injured mice below $7 \%$ of the corresponding wild-type strain. Plasmidbased complementation with lasI and rhlI restored the mortality rate to $93 \%$, indicative for the importance of these systems for virulence. ${ }^{[10]}$ Chemical interference with AHL has been extensively addressed and was recently reviewed for a number of organisms by Geske et al..$^{[9]}$ and Galloway et al. ${ }^{[8]}$ Besides extensive modifications at the side chain of AHL, various attempts to replace the lactone ring were reported
$P$. aeruginosa uses several quorum by the Spring ${ }^{[8]}$ and Blackwell[9] groups. For example, the putative LasR antagonist 3 at $200 \mu \mathrm{M}$ reduced pyocyanin formation by $93 \%$ and simultaneously reduced elastase expression. ${ }^{[11,12]}$ Furthermore, the antagonism of quorum sensing with furanones (e.g. 4), originally isolated from marine algae with antimicrobial effects, was studied in a murine infection model of $P$. aeruginosa and clearance of the bacteria was observed.[13] The pqs system is unique to $P$. aeruginosa and uses 2-heptyl3-hydroxy-4-quinolone (5, PQS) as signaling molecule. ${ }^{[14]}$ Screening for compounds interfering with the biosynthesis of PQS, namely with the acylcarrier protein PqsD, led to the discovery of $6\left(\mathrm{IC}_{50}=35 \mu \mathrm{M}\right)$. ${ }^{[15]}$ Recently, inhibitors of PqsD were developed and showed reduced production of
PQS and diminished biofilm formation in vitro. ${ }^{[16]}$ The Hartmann group also addressed inhibition of PqsR, the receptor of PQS, and the nanomolar inhibitor 7 was discovered, which also showed reduction of pyocycanin production in the PA14 strain, without reducing extracellular levels of PQS. ${ }^{[17]}$ In a recent fragment-based approach, various fragments based on phenylhydroxamic acid (e.g. 8) were studied and interesting agonistic or antagonistic activities were observed, depending on the substitution pattern. ${ }^{[18]}$

In Vibrio spp., a second quorum sensing system was discovered and termed autoinducer-2 (AI-2). This system is believed to allow interspecies communication. The central AI-2 signaling compound is DPD (9), which spontaneously cyclizes and reacts with borate to form boronate esters. Galloway et al. ${ }^{[8]}$ reviewed numerous compounds that interfere with either LuxS, the synthase of DPD, or with its receptors. A C-1 analog of DPD, isobutylDPD $\left(\mathbf{1 0}, \mathrm{IC}_{50}=54 \mathrm{nM}\right)$, was reported by Gamby et al. to completely inhibit AI-2 dependent quorum sensing in E. coli. ${ }^{[19]}$ Interestingly, the phenyl analog 11 neither interfered with AI-2 system in E. coli nor in S. typhimurium, but instead resulted in a reduction of pyocyanin production in $P$. aeruginosa, an organism that does not produce AI-2 itself. Subsequent analysis of both compounds in biofilm assays showed their biofilm-inhibitory activities on $E$. coli and $P$. aeruginosa, respectively. ${ }^{[20]}$

Recent work by Blackwell and coworkers describes 2-aminobenzimidazole derivatives as strong inhibitors of $P$. aeruginosa biofilms. Based on the natural product bromoageliferin, which inhibits quorum sensing, 12 was synthesized and

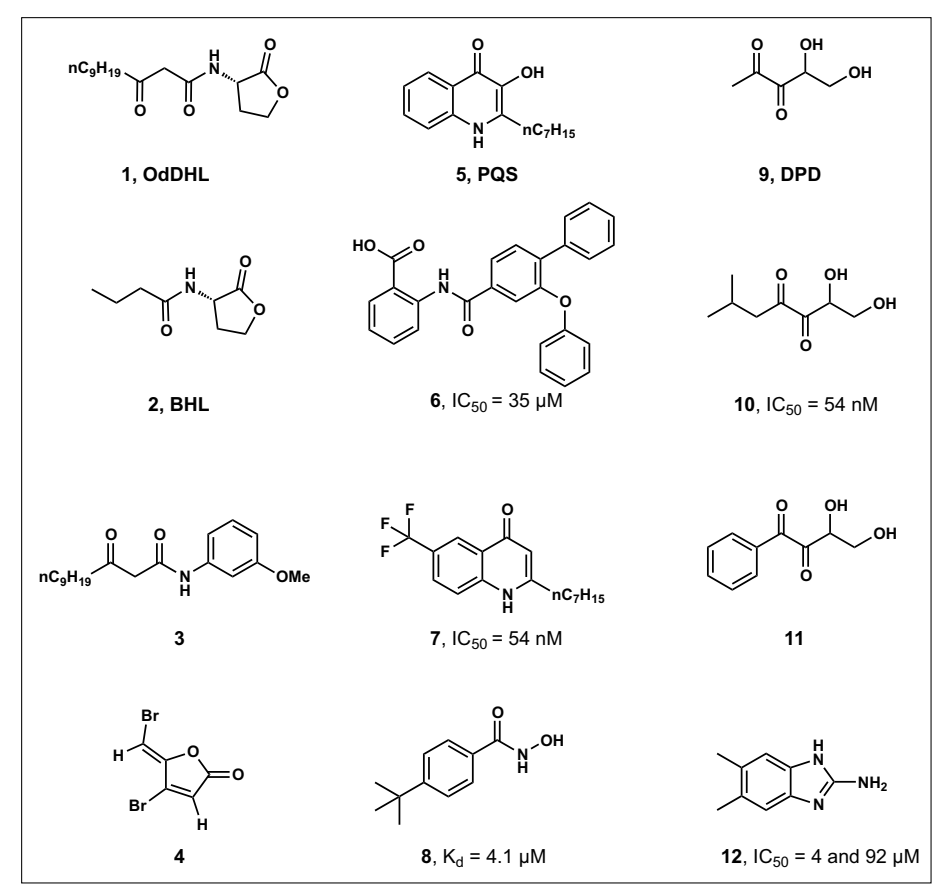

Fig. 2. Natural quorum sensing molecules OdDHL (1), BHL (2), PQS (5) and DPD (9) with analogous inhibitors of quorum sensing. 
found to inhibit biofilm formation and disrupt mature biofilms in vitro $\left(\mathrm{IC}_{50}=4\right.$ and $92 \mu \mathrm{M}$, respectively) and influence both las and $r h l$ quorum sensing systems.[21]

\section{Targeting Adhesive Organelles: Pilicides}

For initial contact with the host cell, pathogens adhere to the surface of the host using adhesive organelles. One strategy to inhibit adhesion and biofilm formation is the interference with biogenesis mechanisms of these organelles. Pili and fimbriae are such rod-like structures bearing adhesins in E. coli, on their outermost position for binding to host cells and establishing biofilms. In Gram-negative bacteria, the chaperone usher pathway (CUP) is a conserved mechanism for the assembly of pili and fimbriae:[22,23] In the bacterial periplasm, subunits of pili or fimbriae are bound by a chaperone and transported to the usher, the site of assembly of the organelle in the outer membrane. In 2001, the term pilicide was coined as a compound that interferes with pilus biogenesis: 2-pyridone derivatives (e.g. 13, Fig. 3) were designed mimetics of the pilus subunit PapG in its interaction with the chaperone PapD with micromolar potencies. ${ }^{[24]}$ To improve the poor solubility of these lipophilic compounds, amines were introduced into pilicide 13, resulting in reduced affinity for the chaperone and potency in live bacteria, which was tentatively assigned to a weakened permeability of the more hydrophilic compound across the bacterial membrane. ${ }^{[25]}$ Later, the morpholino derivative $\mathbf{1 4}$ was able to disrupt pilus biogenesis of the uropathogenic $E$. coli strain UTI89 $\left(\mathrm{IC}_{50}=\right.$ 180-360 $\mu \mathrm{M})$ and thereby disrupt adherence to host cells and biofilm formation. ${ }^{[26]}$ Interestingly, the crystal structure of the complex of 14 with the chaperone PapD contradicted the initial hypothesis of $\mathbf{1 3}$ as a mimic of PapG binding in the cleft of PapD: 14 is bound to a remote lipophilic patch on PapD. This lipophilic patch is part of the interaction site with the usher for pilus assembly, which led to the conclusion that pilicides inhibit the polymerization of pilus subunits and do not disassemble mature pili. Pilicide $\mathbf{1 4}$ was also shown to disrupt the analogous interaction of the chaperone/fimbrial subunit pair FimC/ FimH with its usher FimD with an $\mathrm{IC}_{50}$ of $1.1 \mathrm{mM}$, supporting the notion of a broad spectrum anti-virulence compound against the conserved chaperone-usher pathway. In further SAR studies, lipophilic substituents were introduced adjacent to the sulfur of the thiazole ring ${ }^{[27]}$ and compounds (e.g. 15) with low micromolar pilicide activity were obtained. An anti-virulence mode of action without any influence on the viabili-

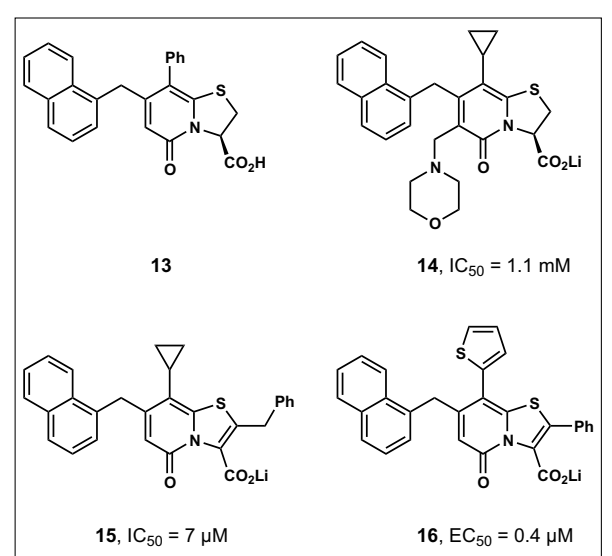

Fig. 3. Pilicides as inhibitors of the biogenesis of adhesive pili.

ty of $E$. coli was determined in a growth assay in presence of various pilicides at 400 $\mu \mathrm{M} \cdot{ }^{[27]}$ In a subsequent extensive study, the compounds were further optimized with 16 being the most potent inhibitor of pilidependent biofilm formation $\left(\mathrm{EC}_{50}=0.4\right.$ $\mu \mathrm{M}){ }^{[28]}$

Recently, Hultgren and co-workers ${ }^{[29]}$ also tested pilicides against $E$. coli curli production, an amyloid proteinacious fiber ${ }^{[30]}$ that is not assembled via the CUP pathway. Introduction of a trifluoromethyl group at the phenyl ring of $\mathbf{1 3}$ showed both inhibition of pilus biogenesis and curli production. ${ }^{[29]}$ A urinary tract infection model was reported: $E$. coli were pretreated with the inhibitor in vitro and after removal of excess of the compound, introduced into the bladder of mice. ${ }^{[29]}$ Six hours post infection, the total bladder bacterial load and intracellular bacterial communities were reduced by a factor of 10 in presence of the small molecule compared to the control population. Interestingly, the same compound induced in vitro polymerization of $\alpha$-synuclein into amyloid fibers, the pathological basis for Parkinson's disease. ${ }^{[31]}$ Introduction of an amino group in 3-position of the pyridone, however, prevented polymerization of $\alpha$-synuclein. ${ }^{[32]}$ Recent work by Kolter and co-workers describes the use of an anti-amyloid approach for the screening of biofilm inhibitors against the Gram-positive model organism Bacillus subtilis. [33]

\section{Targeting Carbohydrate Binding Adhesins}

Besides the targeting of the biogenesis mechanisms of adhesive organelles, direct inhibition of the adhesins is pursued as an anti-biofilm strategy. Inhibiting extracellular adhesins circumvents the disadvantage of intracellular targets with their necessity to overcome the bacterial membrane and resist its efflux pumps. Many bacterial ad- hesins are carbohydrate binding proteins, so-called lectins. ${ }^{[34]}$ Carbohydrates usually display low affinities to their lectin receptors which is overcome in nature through multivalent display of these ligands, for example on the glycocalyx of the cellular envelope. This has inspired chemists to synthesize multivalent ligands with exceptionally high affinities for these lectins (reviewed by Imberty and co-workers ${ }^{[35]}$ ). Although these multivalent compounds have a high potential against topical infections, their poor oral bioavailability limits systemic applications. In addition, selectivity profiles are expected to be broad, due to the promiscuity of the presented unmodified saccharides, equally binding to a variety of host lectins. Therefore, bioavailability and selectivity for the target receptor are being investigated.

Uropathogenic E. coli (UPEC) have the two lectins FimH and PapG located at the tips of fimbriae or pap pili, respectively. Knock-out strains of the individual adhesins resulted in a strongly reduced virulence, indicative for an important role of the corresponding proteins in infection. ${ }^{[36,37]}$ FimH binds to mannosylated glycans present on the urothelium and thereby mediates host cell adhesion and biofilm formation. The crystal structure was first disclosed for its interaction with the chaperone FimC [38] and a preference for mannosides with lipophilic aglycons that are bound by the lectin's tyrosine gate was reported.[39] A number of multivalent mannose-derivative based inhibitors was described, varying mainly in their linker motifs (reviewed by Lindhorst et al. $\left.{ }^{[40]}\right)$. Based on the initial discovery of heptyl mannosides opening the tyrosine gate, biphenyl mannosides ${ }^{[41]}$ were identified as potent inhibitors. Subsequent optimization by the Ernst ${ }^{[42,43]}$ and Hultgren ${ }^{[44,45]}$ labs resulted in the nanomolar FimH inhibitors 18 and 19, which are monovalent (and not multivalent) ligands but represent still very potent lectin antagonists. In both groups, the compounds were tested in a urinary tract infection model in mice and showed efficacy against infection with UPEC. Both intravenous application and the per oral route prior to infection with UPEC led to a decrease of bacterial counts in the bladder up to 4 orders of magnitude. Pharmacokinetic optimization with mouse liver microsomes in vitro and in vivo studies in mice indicate $\mathbf{1 8}$ $\left(\mathrm{K}_{\mathrm{d}}=3.7 \mathrm{nM}\right.$, free acid) as a prodrug with high metabolic stability but low oral availability. ${ }^{[42,43]}$ By introducing phosphates at the hydroxy groups of the mannose moiety, the low oral bioavailability could be overcome by an increased solubility of the resulting prodrug. ${ }^{[46]}$ Furthermore, squaric acid derivatives of mannose ${ }^{[47,48]}$ and indolylphenyl derivatives ${ }^{[49]}$ were reported and selectivity studies ${ }^{[2,50]}$ for FimH an- 


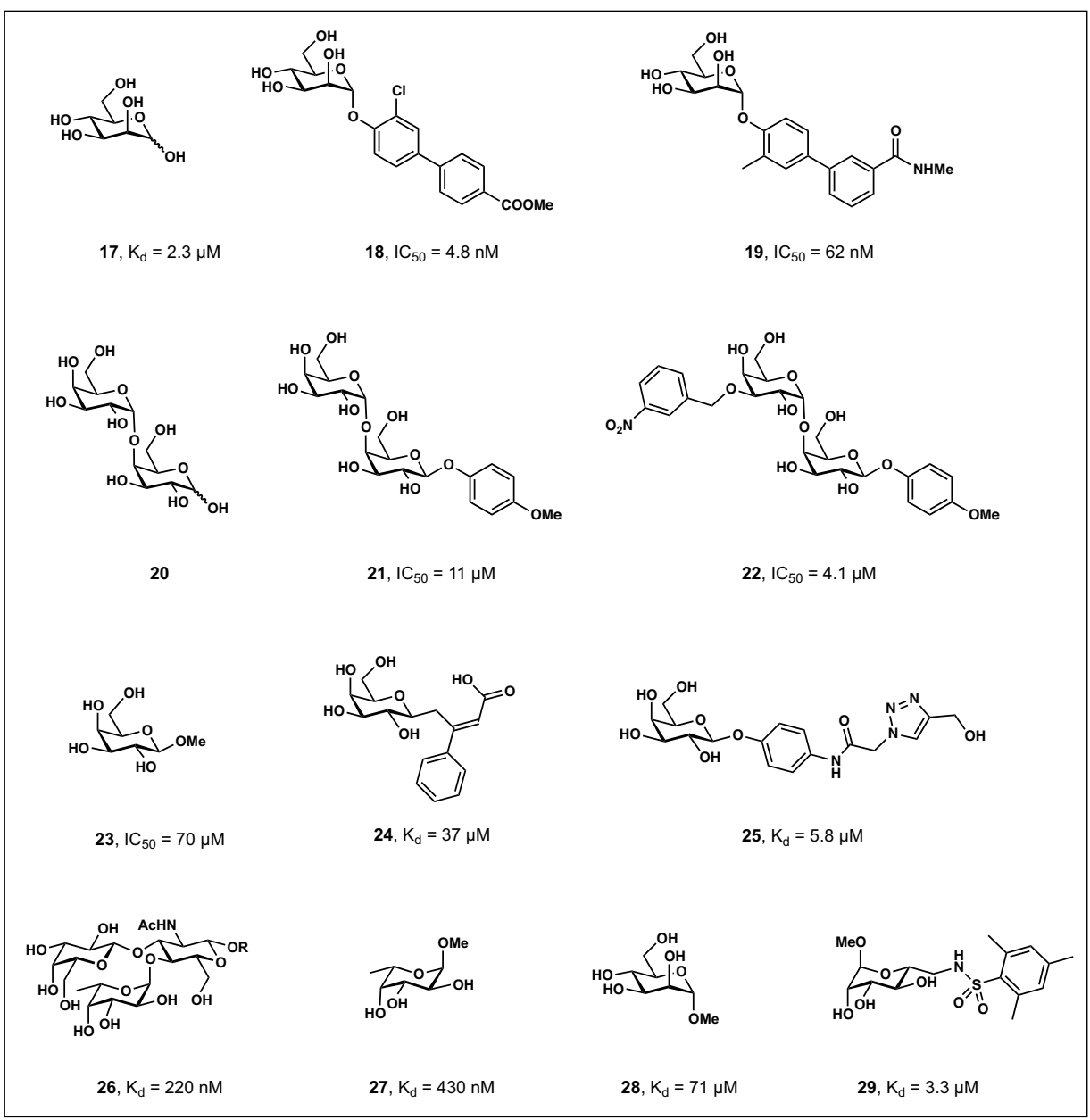

Fig. 4. Carbohydrate ligands and inhibitors of adhesins: E. coli FimH (17-19) and PapG (20, 21), and $P$. aeruginosa LecA (23-25) and LecB (26-29).

tagonists revealed a preference of designed inhibitors for FimH over a set of host mannose-binding lectins. In vitro studies using confocal microscopy demonstrated the potency of mannosylated biphenyl amides (e.g. 19) to disrupt preformed biofilms and the in vivo efficacy against urinary tract infection was shown in chronically infected mice. ${ }^{[44]}$ The pilus lectin PapG mediates adhesion to the galabiose (Gal- $\alpha-1,4-\mathrm{Gal}$, 20) moiety of P-antigen globotetraosyl ceramide present on kidney epithelium, and although its structure[51] was described in 2001, PapG has attracted little attention as a target for medicinal chemistry. However, one report ${ }^{[52]}$ describes galabiosides with affinities in the low micromolar range $(\mathbf{2 1}$ : $\left.\mathrm{IC}_{50}=11 \mu \mathrm{M}, 22: \mathrm{IC}_{50}=4.1 \mu \mathrm{M}\right)$.

$P$. aeruginosa expresses two soluble homotetrameric lectins, LecA and LecB, with specificity for galactose and mannose or fucose, respectively. ${ }^{[53]}$ Both adhesins are virulence factors, controlled by quorum sensing ${ }^{[54]}$ and necessary for biofilm formation. ${ }^{[55,56]}$ Inhalation of a galactose- and fucose-containing aerosol reduced airway infection with $P$. aeruginosa in humans. ${ }^{[57]}$ Furthermore, it was shown in vitro that biofilms can be disintegrated by application of LecA-[55] or LecB-directed ${ }^{[58]}$ inhibi- tors. Similar to FimH, a number of potent multivalent inhibitors for LecA and LecB with varying linking motifs were synthesized (reviewed by Imberty et al.[35]). The crystal structure of LecA was determined of $\beta$-galactosides with lipophilic aglycon due to the presence of a lipophilic patch on the protein surface. ${ }^{[59,60]}$ Consequently, a number of $\mathrm{O}-, \mathrm{S}-$ and $\mathrm{C}-\beta$-galactosides were synthesized and evaluation in competitive binding assays with LecA revealed mid to low micromolar affinities (e.g. 24, 25). ${ }^{[61-63]}$ Pieters et al. reported bivalent galactosides which are thought to bind simultaneously to two of the four carbohydrate binding sites of LecA as concluded from the high potency $\left(\mathrm{IC}_{50}=220 \mathrm{nM}\right) \cdot{ }^{[64]} \mathrm{LecB}$ displays an unusually strong affinity for $\alpha$-fucosides in the high nanomolar range, which could be explained by the crystal structure of the complex: ${ }^{[65]}$ the presence of two calcium ions in the binding site and an additional lipophilic contact of the methyl group contribute to the strong binding. The blood group antigen Lewis ${ }^{\mathrm{a}}(\mathbf{2 6})$, bearing a terminal $\alpha$-fucoside, is the best known monovalent ligand of LecB $\left(\mathrm{K}_{\mathrm{d}}=220 \mathrm{nM}\right)$. $^{[66]}$ Consequently, $\alpha$-fucosides with various aglycons were synthesized, but all derivaand revealed the basis for the high affinity tives exhibited lower affinities than the parent Lewis ${ }^{\mathrm{a}}$ or methyl $\alpha$-fucoside (27). ${ }^{[67,68]}$ This lack in potency increase can be explained by the solvent directed exposure of these substituents upon binding to LecB. Therefore, we used the low affinity ligand methyl $\alpha$-mannoside $\left(\mathbf{2 8}, \mathrm{K}_{\mathrm{d}}=71 \mu \mathrm{M}\right)$ as a lead structure for LecB inhibitors. By introducing amide or sulfonamide substituents in position 6 of mannose, potent inhibitors of LecB (e.g. 29, $\mathrm{K}_{\mathrm{d}}=3.3 \mu \mathrm{M}$ ) and LecB-mediated bacterial adhesion could be obtained. ${ }^{[69]}$ Due to this terminal capping of mannose, a beneficial selectivity profile of these drug-like molecules for the pathogenic lectin over host lectins recognizing terminal mannosides was anticipated. Both classes of compounds differ in their binding mode to LecB, paving the way for two classes of novel lead structures for the treatment of chronic $P$. aeruginosa infections.

In conclusion, various targets to fight chronic infections by blocking biofilm formation or by disintegrating mature biofilms were recently addressed by medicinal chemists. Promising results, especially from interference with quorum sensing and adhesins, must now be further translated into early clinical phases to prevent the aforementioned scenarios of untreatable infections with Gram-negative bacteria.

\section{Acknowledgement}

The authors acknowledge funding from Zukunftskolleg, Graduate School Chemical Biology, Deutsche Forschungsgemeinschaft and Fonds der Chemischen Industrie.

Received: February 28, 2013

[1] 'The bacterial challenge: time to react', European Centre for Disease Prevention and Control, 2009, Technical report.

[2] K. Poole, Clin. Microbiol. Infect. 2004, 10, 12.

[3] M. Chan, 'Combating antimicrobial resistance: time for action', Copenhagen, 2012.

[4] A. E. Clatworthy, E. Pierson, D. T. Hung, Nat. Chem. Biol. 2007, 3, 541.

[5] K. Poole, Front. Microbiol. 2011, 2, 65.

[6] D. Davies, Nat. Rev. Drug Discov. 2003, 2, 114.

[7] N. A. Whitehead, A. M. Barnard, H. Slater, N. J. Simpson, G. P. Salmond, FEMS Microbiol. Rev. 2001, 25, 365 .

[8] W. R. J. D. Galloway, J. T. Hodgkinson, S. D. Bowden, M. Welch, D. R. Spring, Chem. Rev. 2011, 111, 28.

[9] G. D. Geske, J. C. O'Neill, H. E. Blackwell, Chem. Soc. Rev. 2008, 37, 1432.

[10] K. P. Rumbaugh, J. A. Griswold, A. N. Hamood, Microbes Infect. 2000, 2, 1721.

[11] B. Morkunas, W. R. J. D. Galloway, M. Wright, B. M. Ibbeson, J. T. Hodgkinson, K. M. G. O'Connell, N. Bartolucci, M. Della Valle, M. Welch, D. R. Spring, Org. Biomol. Chem. 2012, 10,8452 .

[12] J. T. Hodgkinson, W. R. J. D. Galloway, M. Wright, I. K. Mati, R. L. Nicholson, M. Welch, D. R. Spring, Org. Biomol. Chem. 2012, 10, 6032 . 
[13] M. Hentzer, H. Wu, J. B. Andersen, K. Riedel, T. B. Rasmussen, N. Bagge, N. Kumar, M. A. Schembri, Z. Song, P. Kristoffersen, M. Manefield, J. W. Costerton, S. Molin, L. Eberl, P. Steinberg, S. Kjelleberg, N. Høiby, M. Givskov, EMBO J. 2003, 22, 3803.

[14] H. Huse, M. Whiteley, Chem. Rev. 2011, 111, 152.

[15] D. Pistorius, A. Ullrich, S. Lucas, R. W. Hartmann, U. Kazmaier, R. Müller, ChemBioChem. 2011, 12, 850.

[16] M. P. Storz, C. K. Maurer, C. Zimmer, N. Wagner, C. Brengel, J. C. de Jong, S. Lucas, M. Müsken, S. Häussler, A. Steinbach, R. W. Hartmann, J. Am. Chem. Soc. 2012, 134, 16143.

[17] C. Lu, B. Kirsch, C. Zimmer, J. C. de Jong, C. Henn, C. K. Maurer, M. Müsken, S. Häussler, A. Steinbach, R. W. Hartmann, Chem. Biol. 2012, 19, 381.

[18] T. Klein, C. Henn, J. C. de Jong, C. Zimmer, B. Kirsch, C. K. Maurer, D. Pistorius, R. Müller, A. Steinbach, R. W. Hartmann, ACS Chem. Biol. 2012, 7, 1496.

[19] S. Gamby, V. Roy, M. Guo, J. A. I. Smith, J. Wang, J. E. Stewart, X. Wang, W. E. Bentley, H. O. Sintim, ACS Chem. Biol. 2012, 7, 1023.

[20] V. Roy, M. T. Meyer, J. A. I. Smith, S. Gamby, H. O. Sintim, R. Ghodssi, W. E. Bentley, Appl. Microbiol. Biotechnol. 2013, 97, 2627.

[21] R. Frei, A. S. Breitbach, H. E. Blackwell, Angew. Chem. Int. Ed. 2012, 51, 5226.

[22] G. Waksman, S. J. Hultgren, Nat. Rev. Microbiol. 2009, 7, 765.

[23] W. J. Allen, G. Phan, G. Waksman, Curr. Opin. Struct. Biol. 2012, 22, 500 .

[24] A. Svensson, A. Larsson, H. Emtenäs, M. Hedenström, T. Fex, S. J. Hultgren, J. S. Pinkner, F. Almqvist, J. Kihlberg, ChemBioChem. 2001, 2,915 .

[25] V. Aberg, M. Sellstedt, M. Hedenström, J. S. Pinkner, S. J. Hultgren, F. Almqvist, Bioorg. Med. Chem. 2006, 14, 7563.

[26] J. S. Pinkner, H. Remaut, F. Buelens, E. Miller, V. Aberg, N. Pemberton, M. Hedenström, A. Larsson, P. Seed, G. Waksman, S. J. Hultgren, F. Almqvist, Proc. Natl. Acad. Sci. USA 2006, 103, 17897.

[27] E. Chorell, J. S. Pinkner, G. Phan, S. Edvinsson, F. Buelens, H. Remaut, G. Waksman, S. J Hultgren, F. Almqvist, J. Med. Chem. 2010, 53, 5690.

[28] E. Chorell, J. S. Pinkner, C. Bengtsson, T. S.L. Banchelin, S. Edvinsson, A. Linusson, S. J. Hultgren, F. Almqvist, Bioorg. Med. Chem. 2012, 20, 3128.

[29] L. Cegelski, J. S. Pinkner, N. D. Hammer, C. K. Cusumano, C. S. Hung, E. Chorell, V. Aberg, J. N. Walker, P. C. Seed, F. Almqvist, M. R. Chapman, S. J. Hultgren, Nat. Chem. Biol. 2009, 5, 913 .

[30] L. P. Blanco, M. L. Evans, D. R. Smith, M. P. Badtke, M. R. Chapman, Trends Microbiol. 2012, 20, 66.

[31] I. Horvath, C. F. Weise, E. K. Andersson, E. Chorell, M. Sellstedt, C. Bengtsson, A. Olofsson, S. J. Hultgren, M. Chapman, M. Wolf-Watz, F. Almqvist, P. Wittung-Stafshede, J. Am. Chem. Soc. 2012, 134, 3439.
[32] I. Horvath, M. Sellstedt, C. Weise, L.-M. Nordvall, G. Krishna Prasad, A. Olofsson, G. Larsson, F. Almqvist, P. Wittung-Stafshede, Arch. Biochem. Biophys. 2013, 532, 84.

[33] D. Romero, E. Sanabria-Valentín, H. Vlamakis, R. Kolter, Chem. Biol. 2013, 20, 102.

[34] N. Sharon, Biochim. Biophys. Acta 2006, 1760, 527.

[35] A. Bernardi, J. Jiménez-Barbero, A. Casnati, C. De Castro, T. Darbre, F. Fieschi, J. Finne, H. Funken, K.-E. Jaeger, M. Lahmann, T. K. Lindhorst, M. Marradi, P. Messner, A. Molinaro, P. V. Murphy, C. Nativi, S. Oscarson, S. Penadés, F. Peri, R. J. Pieters, O. Renaudet, J.-L. Reymond, B. Richichi, J. Rojo, F. Sansone, C. Schäffer, W. B. Turnbull, T. Velasco-Torrijos, S. Vidal, S. Vincent, T. Wennekes, H. Zuilhof, A. Imberty, Chem. Soc. Rev. 2013, DOI:10.1039/ C2CS35408J.

[36] S. Langermann, S. Palaszynski, M. Barnhart, G. Auguste, J. S. Pinkner, J. Burlein, P. Barren, S. Koenig, S. Leath, C. H. Jones, S. J. Hultgren, Science 1997, 276, 607.

[37] J. A. Roberts, B. I. Marklund, D. Ilver, D. Haslam, M. B. Kaack, G. Baskin, M. Louis, R. Möllby, J. Winberg, S. Normark, Proc. Natl. Acad. Sci. USA 1994, 91, 11889.

[38] D. Choudhury, A. Thompson, V. Stojanoff, S. Langermann, J. Pinkner, S. J. Hultgren, S. D. Knight, Science 1999, 285, 1061.

[39] J. Bouckaert, J. Berglund, M. Schembri, E. De Genst, L. Cools, M. Wuhrer, C.-S. Hung, J. Pinkner, R. Slättegård, A. Zavialov, D. Choudhury, S. Langermann, S. J. Hultgren, L. Wyns, P. Klemm, S. Oscarson, S. D. Knight, H. De Greve, Mol. Microbiol. 2005, 55, 441.

[40] M. Hartmann, T. K. Lindhorst, Eur. J. Org. Chem. 2011, 3583.

[41] Z. Han, J. S. Pinkner, B. Ford, R. Obermann, W. Nolan, S. A. Wildman, D. Hobbs, T. Ellenberger, C. K. Cusumano, S. J. Hultgren, J. W. Janetka, J. Med. Chem. 2010, 53, 4779.

[42] T. Klein, D. Abgottspon, M. Wittwer, S. Rabbani, J. Herold, X. Jiang, S. Kleeb, C. Lüthi, M. Scharenberg, J. Bezençon, E. Gubler, L. Pang, M. Smiesko, B. Cutting, O. Schwardt, B. Ernst, J. Med. Chem. 2010, 53, 8627.

[43] L. Pang, S. Kleeb, K. Lemme, S. Rabbani, M. Scharenberg, A. Zalewski, F. Schädler, O. Schwardt, B. Ernst, ChemMedChem. 2012, 7, 1404.

[44] C. K. Cusumano, J. S. Pinkner, Z. Han, S. E. Greene, B. A. Ford, J. R. Crowley, J. P. Henderson, J. W. Janetka, S. J. Hultgren, Sci. Transl. Med. 2011, 3, 109ra115.

[45] Z. Han, J. S. Pinkner, B. Ford, E. Chorell, J. M. Crowley, C. K. Cusumano, S. Campbell, J. P. Henderson, S. J. Hultgren, J. W. Janetka, J. Med. Chem. 2012, 55, 3945.

[46] B. Ernst, Patent WO2012/164074A1, 2012.

[47] C. Grabosch, M. Hartmann, J. Schmidt-Lassen, T. K. Lindhorst, ChemBioChem. 2011, 12, 1066.

[48] O. Sperling, A. Fuchs, T. K. Lindhorst, Org. Biomol. Chem. 2006, 4, 3913.

[49] X. Jiang, D. Abgottspon, S. Kleeb, S. Rabbani, M. Scharenberg, M. Wittwer, M. Haug, O. Schwardt, B. Ernst, J. Med. Chem. 2012, 55, 4700 .
[50] M. Scharenberg, O. Schwardt, S. Rabbani, B. Ernst, J. Med. Chem. 2012, 55, 9810.

[51] K. W. Dodson, J. S. Pinkner, T. Rose, G. Magnusson, S. J. Hultgren, G. Waksman, Cell 2001, 105, 733 .

[52] J. Ohlsson, J. Jass, B. E. Uhlin, J. Kihlberg, U. J. Nilsson, ChemBioChem. 2002, 3, 772.

[53] N. Gilboa-Garber, Method. Enzymol. 1982, 83, 378.

[54] K. Winzer, C. Falconer, N. C. Garber, S. P. Diggle, M. Camara, P. Williams, J. Bacteriol. 2000, 182, 6401 .

[55] S. P. Diggle, R. E. Stacey, C. Dodd, M. Cámara, P. Williams, K. Winzer, Environ. Microbiol. 2006, 8, 1095.

[56] D. Tielker, S. Hacker, R. Loris, M. Strathmann, J. Wingender, S. Wilhelm, F. Rosenau, K.-E. Jaeger, Microbiology 2005, 151, 1313.

[57] H.-P. Hauber, M. Schulz, A. Pforte, D. Mack, P. Zabel, U. Schumacher, Int. J. Med. Sci. 2008, 5 , 371.

[58] E. M. V. Johansson, S. A. Crusz, E. Kolomiets, L. Buts, R. U. Kadam, M. Cacciarini, K.-M. Bartels, S. P. Diggle, M. Cámara, P. Williams, R. Loris, C. Nativi, F. Rosenau, K.-E. Jaeger, T. Darbre, J.-L. Reymond, Chem. Biol. 2008, 15, 1249

[59] G. Cioci, E. P. Mitchell, C. Gautier, M. Wimmerová, D. Sudakevitz, S. Pérez, N. Gilboa-Garber, A. Imberty, FEBS Lett. 2003, 555, 297.

[60] N. Garber, U. Guempel, A. Belz, N. GilboaGarber, R. J. Doyle, Biochim. Biophys. Acta 1992, 1116, 331.

[61] Y. M. Chabre, D. Giguère, B. Blanchard, J. Rodrigue, S. Rocheleau, M. Neault, S. Rauthu, A. Papadopoulos, A. A. Arnold, A. Imberty, R. Roy, Chem. Eur. J. 2011, 17, 6545.

[62] R. U. Kadam, M. Bergmann, M. Hurley, D. Garg, M. Cacciarini, M. A. Swiderska, C. Nativi, M. Sattler, A. R. Smyth, P. Williams, M. Cámara, A. Stocker, T. Darbre, J.-L. Reymond, Angew. Chem. Int. Ed. 2011, 50, 10631.

[63] S. Cecioni, J.-P. Praly, S. E. Matthews, M. Wimmerová, A. Imberty, S. Vidal, Chem. Eur. J. 2012, 18, 6250

[64] F. Pertici, R. J. Pieters, Chem. Commun. 2012, $48,4008$.

[65] E. Mitchell, C. Houles, D. Sudakevitz, M. Wimmerova, C. Gautier, S. Pérez, A. M. Wu, N. Gilboa-Garber, A. Imberty, Nat. Struct. Biol. 2002, 9, 918.

[66] S. Perret, C. Sabin, C. Dumon, M. Pokorná, C. Gautier, O. Galanina, S. Ilia, N. Bovin, M. Nicaise, M. Desmadril, N. Gilboa-Garber, M. Wimmerová, E. P. Mitchell, A. Imberty, Biochem. J. 2005, 389, 325.

[67] K. Marotte, C. Sabin, C. Préville, M. MouméPymbock, M. Wimmerová, E. P. Mitchell, A. Imberty, R. Roy, ChemMedChem. 2007, 2, 1328.

[68] M. Andreini, M. Anderluh, A. Audfray, A. Bernardi, A. Imberty, Carbohydr. Res. 2010, $345,1400$.

[69] D. Hauck, I. Joachim, B. Frommeyer, A. Varrot, B. Philipp, H. M. Möller, A. Imberty, T. E. Exner, A. Titz, Proc. International Carbohydrate Symposium, Madrid, 2012 